\title{
The Application of Multimedia Assisted Teaching in Distance Learning: Taking the Oral English Training Program for Fifth Grade Students as an Example
}

\author{
Ireneacho Leveantino
}

\begin{abstract}
This study used descriptive correlational method of study and used quantitative method to determine the level of academic performance of Grade 5 Diamond pupils in English using Modular Distance Learning and the level of academic performance of Grade 5 pupils using video lessons as an aid to Modular Distance Learning and significant difference between the level of academic performance of Grade 5 Diamond pupils in English using Modular Distance Learning only as to using Video Lesson as an aid to Modular Distance Learning. Based on the data gathered, the following findings were revealed only 1 got outstanding performance and 3 from very satisfactory. Moreover, 15 pupils got a satisfactory performance and sadly 7 pupils got a fairly satisfactory performance. Five (5) pupils garnered 19.2 percent belongs to outstanding performance and 15 with 57.7 percent got very satisfactory performance. Thereafter, 5 pupils with 19.2 percent and only 1 pupil with 3.8 percent belong to satisfactory and fairly satisfactory performance. The computed t-value is 5.298 which is less than the critical value of 2.060 with a 0.05 level of significance and a degree of freedom of 4. Hence, the hypothesis that is stated in the null form is to be rejected. Based on the findings, the following conclusions are drawn the pupils may be learned using modular distance learning but it seems that there is something lacking intervention since the pandemic is invading and unpredictably distracting the minds of the pupils. The video lesson used by the researcher as an aid to the modular distance learning platform is very effective despite from universal use of instructional videos to the learners of new normal classes. The $t$ computed value is greater than the tritical value. This means that there is a significant difference between utilizing video lessons as aid and not using intervention during the modular distance learning of the pupils in grade 5. Based on the conclusions of the study, the following recommendations are made that students may go over new concepts in English to enhance their performance in English.21 ${ }^{\text {st }}$ century teachers may scaffold strategies to enhance the performance of the students in English. May the result of PISA and TIMSS be an avenue to create an intervention that will develop the minds of $21^{\text {st }}$-century students in English.The Department of Education may fully support the continuing professional development of students based on the principle of lifelong learning and DepEd's commitment to the development of teachers' potential aimed towards their success in the curriculum.Conduct related free training and seminars to the elementary teachers to help them empower and sustain their knowledge in English.
\end{abstract}

Keywords: Video Lessons, Modular Distance Learning

\section{Context and Rationale}

The State shall protect and promote the right of all citizens to quality education at all levels and shall take appropriate steps to make such education accessible to all (Constitution, 1987). The effort of the government in providing quality education to every Filipino citizen is clearly stated in the constitution of the Philippines and in the different programs and projects of the Department of Education.

The recent global event that significantly struck not only the world's economy but the whole global education sector as well. We were not at all prepared and have not in mind any precautions or whatsoever in dealing with this COVID-19. A pandemic that prevented us from doing what we usually do on a daily basis. An alternative was provided to us, social distancing at its best so with no face-to-face interaction was laid and been implemented. The learning facet drastically changed, and a new learning process was set forth. A "new normal" way of education which paved way to different learning modalities apart from face to face is the safest way and most appropriate in the call of time.

DepEd Secretary Leonor M. Briones introduced a Basic Education Learning Continuity Plan (BE-LCP) as a guideline for the department on how to deliver education in time of the COVID-19 pandemic while ensuring the health, safety, and welfare of all learners, teachers and personnel of DepEd. Another main feature of BE-LCP is the adoption of multiple learning delivery modalities, with blended learning and distance learning as major options. Briones emphasized that online learning is only one option from the menu of learning modalities. These modalities will be offered appropriately depending about the learners' households.

DepEd undersecretary Diosdado San Antonio issued a Memorandum DM-Ci-2020-00162 entitled SUGGESTED STRATEGIES IN IMPLEMENTING DISTANCE LEARNING DELIVERY MODALITIES (DLDM) FOR SCHOOL YEAR 2020-2021, stating clearly that the "directive of the Office of the President that no face-to-face classes shall be held until the vaccine for COVID-19 becomes available, the distance learning delivery modalities (DLDM) shall be implemented this SY 2020-2021". As stated, Distance Learning may be implemented through the following delivery modalities: a. Modular Distance Learning (MDL) b.1. Digital Modular Distance Learning (DMDL) b.2. Printed Modular Distance Learning (PMDL) b. Online Distance Learning (ODL) c. TV-Video/Radio-based Instruction (TV-Video/RBI) c.1. TV-Video (SLM-based) c.2 TV-Video (MELCs Mapped) c.3. Radio-Based Instruction (RBI) d. Blended Distance Learning (BDL).

Among the cited modalities, Bulan North Central School-B has implemented the Modular Learning Delivery. With this, the researcher would like to determine the extent of how the teachers handle classes through this modality. Due to this, teachers play a vital role in all educational stages. To continue the learning process, our department issued several orders and memoranda to ensure that we immediately give 
aid to this problem. Bulan North Central School-B is one of the public schools that is facing this dilemma especially in this time of pandemic.

In the data gathered for the pastquarters, the turnout of the activities in English, the learner'sscores were low. There is an impression that they are having a hard time though it is a Self-Learning module. The teacher is now facing a big block of challenge on how they will improve their pupils' performance.

This action research aims toimprove the academic performance of Grade 5 pupils in English.

\section{Action Research Question/s}

This study attempts to answer the following:

1) What is the level of academic performance of Grade 5 Diamond pupils in English using Modular Distance Learning?

2) What is the level of academic performance of Grade 5 pupils using video lesson as aid to Modular Distance Learning?

3) Is there a significant difference between the level of academic performance of Grade 5 Diamond pupils in English using Modular Distance Learning only as to using Video Lesson as aid to Modular Distance Learning?

\section{Proposed Innovation, Intervention and Strategy}

The proposed innovation is to provide video lessons guided by the Learning Activity Sheets.Teachers and the school head would be involved to this study. After the conduct of the innovation, a five-point linear numerical scale will be used to measure the acceptance level of the innovation.

\section{Action Research Methods}

a) Participants and/or other Sources of Data and Information

The respondents to this study are 26 Grade 5 Diamond pupils of Bulan North Central School-B.

The records of pupils' summative tests in English will be part of the source of data.

b) Data Gathering Methods

This research focused on Quantitative Data Collection Method where the researcher used a teacher-made-test to pupils to answer and this would form part of the document analysis. Also, interview with guide would also be utilized to gather data.

c) Data Analysis Plan

The data that gathered and be treated with utmost confidentiality and mean computation for each question would be done to gather correct and relevant data for each response. Using individual performance level of the pupils using Modular distance learning and Using Video lesson as aid to Modular distance learning. After the retrieval of the examination, the researcher asked expert in statistics to treat the data and find if there is a significant difference between using video lesson and not during the modular distance learning platform of the pupils.

\section{Discussion of Results and Reflection}

This chapter presented the analysis and interpretation of the data gathered from the respondents. Appropriate tables which were sequentially arranged were used to answer the problems being sought in the study. This may discuss the results of the study on video lesson as aid to modular distance learning in improving academic performance of grade 5 pupils in English.

a) The level of academic performance of Grade 5 Diamond pupils in English using Modular Distance Learning

Table 1: Academic Performance of Grade 5 Pupils using Modular Distance Learning

\begin{tabular}{|c|c|c|c|}
\hline Performance & $\mathrm{F}$ & Percentage & $\mathrm{I}$ \\
\hline $90-100$ & 1 & $3.8 \%$ & $\mathrm{O}$ \\
\hline $85-89$ & 3 & $11.5 \%$ & $\mathrm{VS}$ \\
\hline $80-84$ & 15 & $57.7 \%$ & $\mathrm{~S}$ \\
\hline $75-79$ & 7 & $26.9 \%$ & $\mathrm{FS}$ \\
\hline Total & 26 & $100 \%$ & \\
\hline
\end{tabular}

It can be gleaned in the table that almost 26 pupils passed the examination but they belong to lower scores and lower performance levels. Only 1 got the outstanding performance and 3 from very satisfactory. Moreover, 15 pupils got a satisfactory performance and sadly 7 pupils got a fairly satisfactory performance.

It means that pupils maybe learned using modular distance learning but it seems that there is something lacking of intervention since the pandemic is invading and unpredictably distracting the minds of the pupils. It implies that it really needs to utilized interventions like video lessons, contextualized learning materials and other strategic intervention materials to uplift and develop the retention of knowledge of the pupils most specially in English.

Somehow technology plays a vital role in enhancing the academic performance of the pupils like developing the reading literacy of the pupils. This claimed was supported by O'brien, Habib and Onnis (2019) that Technology plays an increasingly important role in educational practice, including interventions for struggling learners. This study focuses on the efficacy of tablet-based applications for the purpose of supplementing early English literacy intervention with primary grades 1 and 2 children. The children were identified for learning support programs within Singaporean schools, which follow a bilingual policy, meaning children were learning reading in English plus an additional language. One hundred forty-seven children across seven schools participated (Mean age $=6.66$ ). Within learning support classrooms, triplets of students matched on basic reading skills were randomly assigned to one of three groups: (1) phoneme-level, (2) rime-level, or (3) word-level focused interventions. All groups performed reading skills activities on iPads, across two phases over a 14-week period. Assessments for word reading accuracy and fluency, pseudoword decoding accuracy and fluency, and spelling were administered at four time points, pre- and post- 
intervention. Additional baseline measures were taken to assess individual differences in phonological awareness, orthographic awareness, general cognitive ability, statistical learning, and bilingual vocabulary knowledge. Mixed model analysis was conducted on the pre- to post-test measures across the two phases of the intervention (focused on accuracy then fluency). All groups made gains across the different literacy measures, while the phoneme-level intervention showed an advantage over the rime-level intervention, but not the word-level intervention, for decoding. There were also moderating effects of individual differences on outcomes. The general pattern of results showed an advantage of the word-level intervention for those with poorer phonological awareness for reading fluency; and a phoneme-level intervention advantage for those with poorer statistical learning ability. Children's bilingual group (English plus Mandarin, English plus Malay, or English plus Tamil) also showed differential effects of the type of intervention (e.g., phoneme- or word-level) on different outcome measures. These results, along with data collected from the tablets during the intervention, suggest the need to examine the interplay between different types of technology-based interventions and individual differences in learning profiles.

b) The level of Academic Performance of Grade 5 pupils using Video Lesson as aid to Modular Distance Learning

Table 2: Academic Performance of Grade 5 Pupils using Video Lesson as aid to Modular Distance Learning

\begin{tabular}{|c|c|c|c|}
\hline Performance & F & Percentage & I \\
\hline $90-100$ & 5 & $19.2 \%$ & O \\
\hline $85-89$ & 15 & $57.7 \%$ & VS \\
\hline $80-84$ & 5 & $19.2 \%$ & S \\
\hline $75-79$ & 1 & $3.8 \%$ & FS \\
\hline Total & 26 & $100 \%$ & \\
\hline
\end{tabular}

It was assembled in the table the results of academic performance of the grade 5 pupils in English using video lessons as aid to the Modular Distance Learning. The results were somehow different compared to the results without using intervention during the delivering of knowledge to the pupils' despite from pandemic. It can be gleaned in the table that 5 pupils garnered 19.2 percent belongs to outstanding performance and 15 with 57.7 percent got very satisfactory performance. Thereafter, 5 pupils with 19.2 percent and only 1 pupil with 3.8 percent belongs to satisfactory and fairly satisfactory performance.

This result means that the video lesson used by the researcher as aid to the modular distance learning platform is very effective despite from universal use of instructional videos to the learners of new normal classes. This implies that using video instructional materials for learners brought new hope of developing knowledge of learners even new normal classes is still adjusting and finding ways to enhance the performance of the learners.

This claimed was supported by Joyner, Goel and Ou (2019) that Despite the ubiquitous use of instructional videos in both formal and informal learning settings, questions remain largely unanswered on how to design and develop video lessons that are often used as the primary method for delivering instruction in online courses. In this study, we experimented with a model of seven principles drawn from instructional design theories for designing and developing video lessons for an online graduate course. Feedback was collected from students through surveys on their perceptions of the effectiveness of the video lessons and the overall course quality for eight semesters. This paper shares the instructors' experience on the design and development of the video lessons as well as the survey findings.

c) Significant Difference between the level of academic performance of Grade 5 Diamond pupils in English using Modular Distance Learning only as to using Video Lesson as aid to Modular Distance Learning

Table 3: Significant Difference between Academic Performance using MDL and Using Video Lesson as aid to MDL

\begin{tabular}{|c|c|}
\hline Statistical Bases & Statistical Analysis \\
\hline Degree of freedom $(\mathrm{df})$ & 25 \\
\hline Level of Significance & 0.05 \\
\hline $\mathrm{t}$ critical value & 2.060 \\
\hline $\mathrm{t}$ computed value & 7.331 \\
\hline Decision on $\mathrm{H}_{\mathrm{o}}$ & Rejected \\
\hline Conclusion & Significant \\
\hline
\end{tabular}

The computed t-value is 5.298 which is less than the critical value of 2.060 with a 0.05 level of significance and a degree of freedom of 4 . Hence, the hypothesis that is stated in the null form is to be rejected.

The result shows that the $t$ computed value is greater than the $\mathrm{t}$ critical value. This means that there is a significant difference between the utilizing video lessons as aid and not using intervention during the modular distance learning of the pupils in grade 5. The decision indicated that there was a significantly different from each other. This implies that the academic performance utilizing video lessonwas higher than not using video lessons. Meaning, the pupils were accepting and can really adjust using technology in the midst of new normal classes.

This claimed was supported by Donkor (2020) the study sought to examine the instructional effectiveness of videobased instructional materials vis-à-vis traditional print-based instructional materials for teaching distance learners of a Block-Laying and Concreting practical skills programme. An experimental design was used and participants were randomly assigned to two treatment groups: Users of videobased instructional materials or users of print-based instructional materials. A researcher-designed performance test and an achievement test of 20 multiple-choice items were used to collect data from 34 participants who used print-based instructional materials and 35 participants who used video-based instructional materials to learn practical skills. The instruments were based on the instructional objectives of lessons on mortar and wall finish. Pilot test data for the achievement test yielded Cronbach's alpha of 0.84. Descriptive statistics and t-test at a 0.05 level of significance were used to analyze the data. The results indicated that the two instructional materials were pedagogically equivalent in terms of theoretical knowledge acquired. Practical skills acquired, however, were 
significantly higher among users of video-based instructional materials. Finally, users of video-based instructional materials displayed significantly superior craftsmanship.

\section{Findings, Conclusions and Recommendation}

Findings

Based from the data gathered, the following findings were revealed:

1) Only 1 got the outstanding performance and 3 from very satisfactory. Moreover, 15 pupils got a satisfactory performance and sadly 7 pupils got a fairly satisfactory performance.

2) Five (5) pupils garnered 19.2 percent belongs to outstanding performance and 15 with 57.7 percent got very satisfactory performance. Thereafter, 5 pupils with 19.2 percent and only 1 pupil with 3.8 percent belongs to satisfactory and fairly satisfactory performance.

3) The computed t-value is 5.298 which is less than the critical value of 2.060 with a 0.05 level of significance and a degree of freedom of 4 . Hence, the hypothesis that is stated in the null form is to be rejected.

\section{Conclusions}

Based from the findings, the following conclusions are drawn;

1) The pupils maybe learned using modular distance learning but it seems that there is something lacking of intervention since the pandemic is invading and unpredictably distracting the minds of the pupils.
2) The video lesson used by the researcher as aid to the modular distance learning platform is very effective despite from universal use of instructional videos to the learners of new normal classes.

3) The t computed value is greater than the t critical value. This means that there is a significant difference between the utilizing video lessons as aid and not using intervention during the modular distance learning of the pupils in grade 5 .

\section{Recommendations}

Based from the conclusions of the study, the following recommendations are made:

1) Students may go over new concepts in English to enhance their performance in English.

2) $21^{\text {st }}$ century teachers may scaffold strategies to enhance the performance of the students in English. May the result of PISA and TIMSS be an avenue to create intervention that will develop minds of $21^{\text {st }}$ century students in English.

3) The Department of Education may fully support the continuing professional development of students based on the principle of lifelong learning and DepEd's commitment to the development of teacher's potential aimed towards their success in the curriculum.

4) Conduct related free trainings and seminars to the elementary teachers to help them empowered and sustained their knowledge in English.

\section{Action Research Work Plan and Timelines}

\begin{tabular}{|c|c|c|c|c|c|c|c|c|c|c|c|c|}
\hline Activities/Tasks & \multicolumn{4}{|c|}{ November 2021} & \multicolumn{4}{|c|}{ December 2021} & \multicolumn{4}{|c|}{ January 2022} \\
\hline PRE-IMPLEMENTATION & W1 & W2 & W3 & W4 & W1 & $\mathrm{W} 2$ & W3 & W4 & W1 & W2 & W3 & W4 \\
\hline Preparation of Action Research Proposal & & & & & & & & & & & & \\
\hline Submission and Seeking of Approval & & & & & & & & & & & & \\
\hline IMPLEMENTATION & & & & & & & & & & & & \\
\hline Orientation to parent/pupils' respondents & & & & & & & & & & & & \\
\hline Reproduction of Checklist & & & & & & & & & & & & \\
\hline Distribution of Checklist to respondents & & & & & & & & & & & & \\
\hline Status monitoring & & & & & & & & & & & & \\
\hline Retrieval & & & & & & & & & & & & \\
\hline Data Gathering & & & & & & & & & & & & \\
\hline Data Analysis & & & & & & & & & & & & \\
\hline POST IMPLEMENTATION & & & & & & & & & & & & \\
\hline Finalization and submission of the Completed Action Research & & & & & & & & & & & & \\
\hline
\end{tabular}

\section{Cost Estimates}

\begin{tabular}{|c|c|c|}
\hline ACTIVITIES / TASKS & RESOURCES NEEDED & AMOUNT \\
\hline \multicolumn{3}{|l|}{ PRE-IMPLEMENTATION } \\
\hline Preparation of Action Research Proposal & Purchase of 1 printer L3110 & $8,000.00$ \\
\hline Submission and Seeking of Approval & $\begin{array}{c}1 \text { Ream bond paper @ } 250.00 \text { each } \\
1 \text { bot E003 (Black) @ } 300.00 \text { each } \\
1 \text { bot E003 (Magenta) @ } 300.00 \text { each } \\
1 \text { bot E003 (Yellow) @ } 300.00 \text { each } \\
1 \text { bot E003 (Cyan) @ } 300.00 \text { each } \\
4 \text { pcs a4 folder @ } 10.00 \text { each } \\
4 \text { pcs fastener @ } 2.50 \text { each } \\
\text { Transportation allowance (School to SDO and vice versa) }\end{array}$ & $\begin{array}{l}250.00 \\
300.00 \\
300.00 \\
300.00 \\
300.00 \\
40.00 \\
10.00 \\
850.00\end{array}$ \\
\hline \multicolumn{3}{|l|}{ IMPLEMENTATION } \\
\hline Orientation to faculty/ parent respondents & - & \\
\hline
\end{tabular}




\begin{tabular}{|c|c|c|}
\hline Reproduction of Checklist & Corresponds to the number of pupils \\
\hline Distribution of Checklist to respondents & - \\
\hline Status monitoring & - \\
\hline Retrieval & - \\
\hline Data Gathering & - \\
\hline Data Analysis & & \\
\hline POST IMPLEMENTATION & Binding Cost & \\
\hline Finalization and submission of the Completed Action Research & Transportation Expenses & 500.00 \\
\hline
\end{tabular}

\section{Plans for Dissemination and Utilization}

The result of this study will be disseminated through the SGOD Research and Planning Team supervision. The same copy will be given to the SDO part of responding to one of the most immediate needs in this time of pandemic.

\section{References}

[1] Department of Education. Press Release: Briones, education ministers unite to ensure learning continuity amid COVID-19. Retrieved 2020 from https://www.deped.gov.ph/2020/06/24/

[2] Department of Education. Deped Memo: suggested strategies in implementing Distance Learning Delivery Modalities (DLDM) for school yeaer 2020-2021. Retrieved $2020 \quad$ from https://www.depedmandaluyong.org

[3] Donkor, Francis,. The Comparative Instructional Effectiveness of Print-Based and Video-Based Instructional Materials for Teaching Practical Skills at a Distance, https://www.erudit.org/en/journals/irrodl/1900-v1n1 irrod105150/1067797ar/abstract/retrieved January 6, 2022.

[4] Ou, Chaohua; Joyner, David A.; Goel, Ashok K., Designing and Developing Video Lessons for Online Learning: A Seven-Principle Model, Online Learning, v23 n2 p82-104 Jun 2019

[5] O'Brien, Beth A.,Malikka Habib,Luca Onnis, Technology-Based Tools for English Literacy Intervention: Examining Intervention Grain Size and Individual Differences, National Institute of Education, Nanyang Technological University, Singapore, Singapore 